\title{
Abnormal Uterine Bleeding - A Clinico-pathological Study
}

\author{
Sarita $^{1}$, Nisha J Marla ${ }^{1 *}$, Nagarathna ${ }^{2}$ and Jayaprakash C S ${ }^{1}$ \\ ${ }^{1}$ Department of Pathology, Father Muller Medical College \\ ${ }^{2}$ Department of OBG, Father Muller Medical College \\ ${ }^{3}$ Department of Pathology, Father Muller Medical College
}

\begin{abstract}
Background: Abnormal Uterine Bleeding (AUB) can occur at any age in a woman`s reproductive period and needs to be assessed very carefully and immediately. When it occurs in the older age group, a more meticulous screening for malignancy is imperative so that treatment can be more radical. Dilatation and curettage is a simple, cost effective, safe and a reliable investigation and it gives us a direct access to the target organ.

Methods: Study was conducted prospectively on 162 patients presenting with AUB in reproductive, perimenopausal and postmenopausal age group. All the endometrial samples procured from the endometrial curettage were fixed in 10\% buffered formalin for $12-24$ hours, processed in the automated tissue processor, cut and stained with Hematoxylin \& Eosin (H \& E) stain and were finally studied in detail for the morphological findings under light microscopy.

Result: In our study Secretory endometrium was most common type, which was followed by Proliferative endometrium. Disordered proliferative endometrium and Endometrial hyperplasia were the commonest histopathological patterns seen in AUB of organic type. Endometrial carcinoma was seen more commonly in postmenopausal age group. Further, in our study Mc Cluggage criteria was applied to all the samples to categorize endometrial samples which were unassessable and inadequate.

Conclusion: Evaluation of Endometrial samples is important in all patients with Abnormal Uterine Bleeding (AUB) to find out the Organic Pathology. Histopathological typing of endometrium is crucial for appropriate therapy. Its interpretation is quite challenging and also may show considerable interobserver variability. In AUB, the endometrial samples should be taken during the bleeding episode itself. Dilatation and curettage is a simple, cost effective, safe and reliable investigation and gives us a direct access to the target organ.
\end{abstract}

Keywords: Abnormal Uterine Bleeding, Endometrial Samples, Histomorphology, Clinico-Pathological Study.

\section{Introduction}

Abnormal uterine bleeding (AUB) is one of the commonest presenting complaint in gynecology out-patient department. The underlying causes may be organic or non-organic. The prevalence increases with age, peaking just prior to menopause. As most cases are associated with anovulatory menstrualcycles,particularlyadolescentandperimenopausal women are more vulnerable ${ }^{[1,2]}$. Endometrium is the best accessible tissue for histopathological evaluation of uterine bleeding. Several methods are used for endometrial sampling among which the dilatation of the cervix and curettage of the uterine cavity remains the gold standard in the assessment of AUB. It has several advantages over other diagnostic methods. It is simple, cost effective, safe and a reliable investigation and it gives us a direct access to the target organ ${ }^{[3,4,5]}$. Present study evaluates the spectrum of histomorphological pattern of endometrium in identifying the endometrial causes of AUB.

\section{Materials and Methods}

A prospective study of 162 clinically diagnosed cases of AUB in reproductive, perimenopausal and postmenopausal women from our hospital were included. Clinical details of the patients with regard to age, parity, last menstrual period (LMP), pattern and duration of abnormal bleeding, obstetric history, use of exogenous hormones, sonological findings and clinical diagnosis were collected from laboratory requisition form or case records available from Medical Records Department. All the endometrial samples procured from endometrial curettage were fixed in $10 \%$ buffered formalin for $12-24$ hours. Then tissue was processed in the tissue processor, using the Automatic tissue processor MICROM ST P 120 Program.

The specimens were then embedded in paraffin wax and blocks were cut at 3-5 $\mu \mathrm{m}$ thickness. Sections were stained with Hematoxylin and Eosin stains and were reviewed, the pattern of uterine histopathological changes were identified and classified. All the data was entered into Microsoft Excel 2010 spread sheet and were analyzed. Analysis was done in the form of percentages and proportions.

\section{Result}

Our study included a total of 162 cases of AUB. Histomorphological and clinical evaluation of all cases 
were performed. The results of the study are discussed as follows:

\section{Age Distribution}

Majority of cases, 78 patients were in perimenopausal $40-50$ years age group, followed by 43 cases in $<40$ years reproductive age group and 41 cases in $>50$ years postmenopausal age group.

\section{Histopathological Patterns: (Table 1)}

Out of 162 cases of AUB, majority showed Secretory endometrium in 46 cases, followed by proliferative endometrium in 32 cases. Out of 17 cases diagnosed as endometrial hyperplasia, 12 cases were simple hyperplasia without atypia, 2 cases were simple hyperplasia with atypia and complex hyperplasia without atypia each and 1 case was complex hyperplasia with atypia. Disordered proliferative endometrium (DPE) was seen in 15 cases followed by endometrial polyp in 12 cases.

\section{Endometrial Patterns in Relation to Age:}

\section{(Table 2)}

Among 43 cases, who presented in reproductive age group of $<40$ yrs. 22 cases showed secretory endometrium and 07 cases showed proliferative endometrium. Disordered proliferative endometrium was seen in 04 cases, endometrial polyp in 3 cases, simple hyperplasia without atypia in 2 cases. Complex hyperplasia with atypia, pill endometrium, irregular menstruation in 1 case each and 2 cases were unassesble.

In perimenopausal age group of 40-50 yrs, out of 78 cases 19 cases of secretory and proliferative endometrium each were noted, which was followed by 9 cases of Disordered proliferative endometrium (Fig 1), 7 cases of Simple hyperplasia without atypia (Fig 2), unacessible in 6 cases, irregular maturation in 5 cases, pill endometrium in 5 cases, endometrial polyp in 3 cases and 2 cases of Complex Hyperplasia without atypia (Fig 3) and 2 cases of inadequate sample and 1 case of Endometrial carcinoma (Fig 4).

In post-menopausal age group of $>50$ yrs., out of 41 cases, 06 cases were diagnosed as Proliferative endometrium and endometrial polyp each (Fig 5), followed by 5 cases of secretory endometrium, 4 cases of endometrial carcinoma. 3 cases of simple hyperplasia without atypia, atrophic endometrium and inadequate each was reported. 2 cases of simple hyperplasia with atypia, disordered hyperplasia and irregular maturation each were noted (Table 2). By using Mc Cluggage criteria, we classified samples into unassessable in 4 cases and inadequate in 4 cases. (Fig 6).

Table 1: Histomorphological Patterns of Endometrium.

\begin{tabular}{|l|l|l|}
\hline Type of Endometrium & No. of Cases $\mathbf{( n = 1 6 2 )}$ & Percentage \\
\hline SEM & 46 & $28.39 \%$ \\
\hline PEM & 32 & $19.75 \%$ \\
\hline Atrophic EM & 03 & $1.85 \%$ \\
\hline Pill Endometrium & 07 & $4.32 \%$ \\
\hline DPE & 15 & $9.26 \%$ \\
\hline SH without atypia & 12 & $7.41 \%$ \\
\hline SH with Atypia & 02 & $1.23 \%$ \\
\hline CH without atypia & 02 & $1.23 \%$ \\
\hline CH with atypia & 01 & $0.62 \%$ \\
\hline Endometrial Polyp & 12 & $7.41 \%$ \\
\hline EM Carcinoma & 05 & $3.09 \%$ \\
\hline Irregular maturation & 08 & $4.94 \%$ \\
\hline Unassessable & 12 & $7.41 \%$ \\
\hline Inadequate & 05 & $3.09 \%$ \\
\hline
\end{tabular}

(SEM- secretory endometrium, PEM-prolifeartive endometrium, EM-endometrium, DPE-disordered proliferative endometrium, SH-simple hyperplasia, CH- complex hyperplasia)

Table 2: Endometrial patterns in relation to Age.

\begin{tabular}{|c|c|c|c|c|}
\hline Type of Endometrium & $\begin{array}{l}\text { No. of } \\
\text { ( } n=162 \text { cases) }\end{array}$ & $\begin{array}{l}<40 y r s \\
(n=43)\end{array}$ & $\begin{array}{l}40-50 y r s \\
(n=78)\end{array}$ & $\begin{array}{l}>50 y r s \\
(n=41)\end{array}$ \\
\hline SEM & $46(28.40 \%)$ & $22(51.16 \%)$ & $19(24.36 \%)$ & $05(12.20 \%)$ \\
\hline PEM & $32(19.75 \%)$ & $07(16.28 \%)$ & $19(24.36 \%)$ & $06(14.63 \%)$ \\
\hline Atrophic EM & $03(1.85 \%)$ & - & - & $03(7.32 \%)$ \\
\hline
\end{tabular}




\begin{tabular}{|c|c|c|c|c|}
\hline Type of Endometrium & $\begin{array}{l}\text { No. of } \\
\text { ( } n=162 \text { cases) }\end{array}$ & $\begin{array}{l}<40 y r s \\
(n=43)\end{array}$ & $\begin{array}{l}40-50 y r s \\
(n=78)\end{array}$ & $\begin{array}{l}>50 y r s \\
(n=41)\end{array}$ \\
\hline Pill Endometrium & $07(4.32 \%)$ & $01(2.33 \%)$ & $05(6.41 \%)$ & $01(2.44 \%)$ \\
\hline DPE & $15(9.26 \%)$ & $04(9.30 \%)$ & $09(11.54 \%)$ & $02(4.88 \%)$ \\
\hline SH without atypia & $12(7.41 \%)$ & $02(4.65 \%)$ & $07(8.97 \%)$ & $03(7.32 \%)$ \\
\hline SH with Atypia & $02(1.23 \%)$ & - & - & $02(4.88 \%)$ \\
\hline $\mathrm{CH}$ without atypia & $02(1.23 \%)$ & - & $02(2.56 \%)$ & - \\
\hline $\mathrm{CH}$ with atypia & $01(0.6 \%)$ & $01(2.33 \%)$ & - & - \\
\hline Endometrial Polyp & $12(7.41 \%)$ & $03(6.97 \%)$ & $03(3.85 \%)$ & $06(14.63 \%)$ \\
\hline EM Ca & $05(3.09 \%)$ & - & $01(\mathbf{1 . 2 8} \%)$ & 04(9.75\%) \\
\hline Irregular maturation & $08(4.94 \%)$ & $01(2.33 \%)$ & $05(6.41 \%)$ & $02(4.88 \%)$ \\
\hline Unassessable & $12(7.41 \%)$ & $02(4.65 \%)$ & $06(7.70 \%)$ & 04(9.75\%) \\
\hline Inadequate & $05(3.1 \%)$ & - & $02(2.56 \%)$ & $03(7.32 \%)$ \\
\hline
\end{tabular}

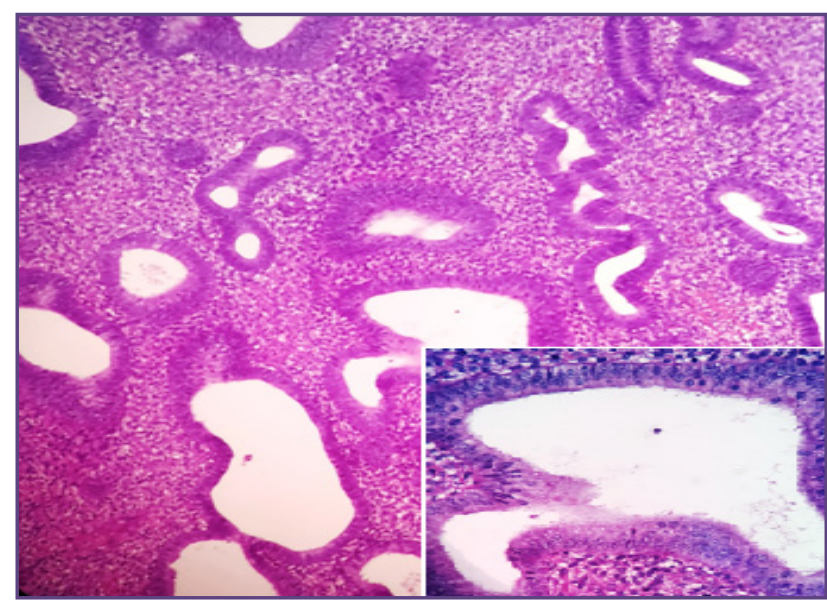

Fig. 1: Photomicrograph showing tubular to few cystically dilated glands in a variably compact stroma. Occasional glands show tubal metaplasia - Disordered Proliferative Endometrium. H\&E, 40X (Inset showing ciliary metaplasia - 400X).

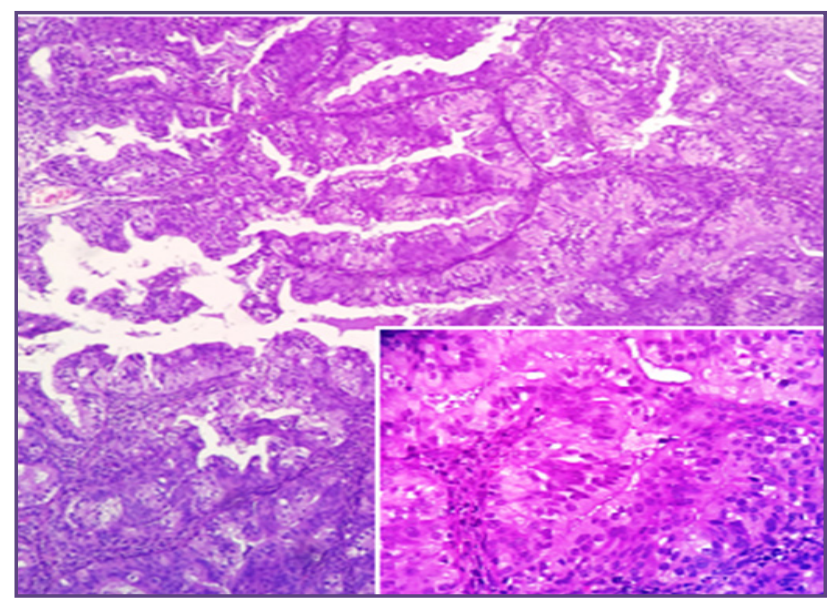

Fig. 3: Photomicrograph showing crowding of the glands which shows complex budding (figures in glove appearance) lined by bland epithelium. - Complex hyperplasia without atypia. H\&E, 40X (Inset - 400X).

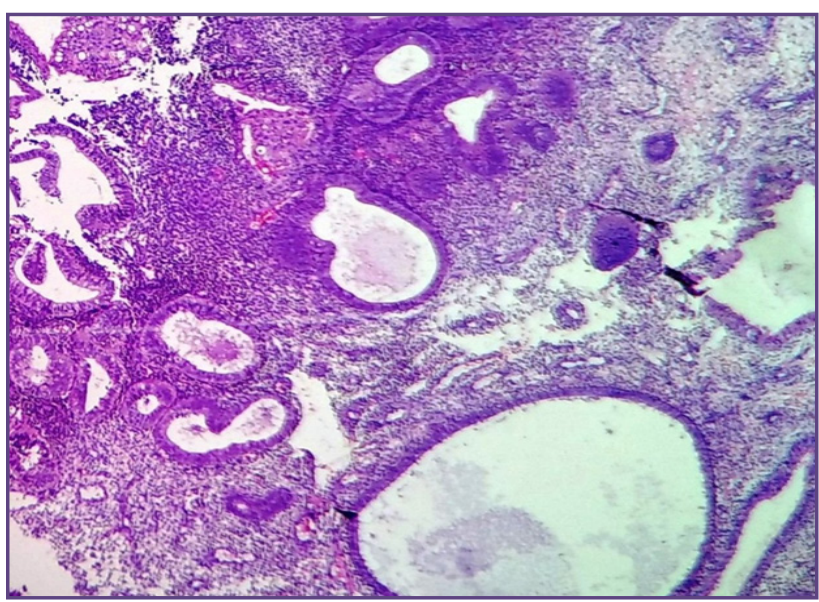

Fig. 2: Photomicrograph showing variably sized endometrial glands, many cystically dilated glands are noted with few glands with simple budding pattern Simple Hyperplasia without atypia. H\&E, 40X.

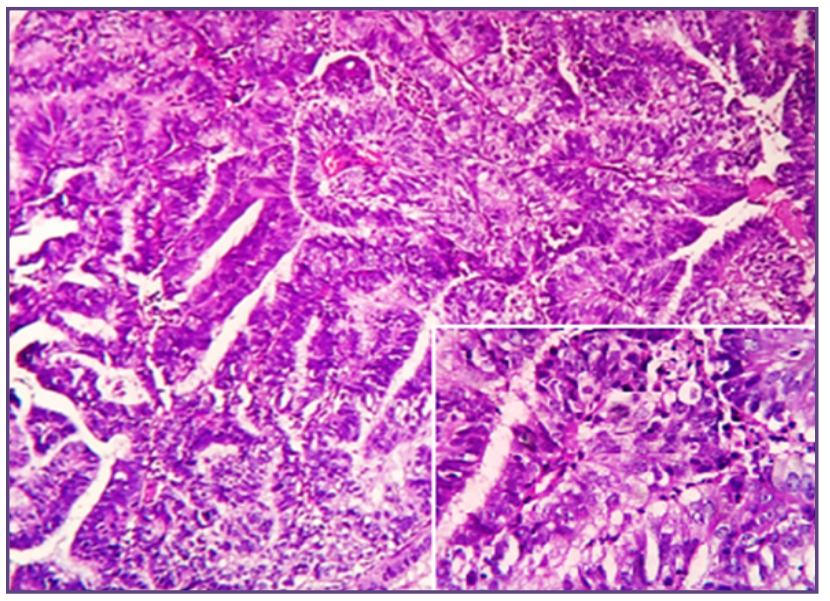

Fig. 4: Photomicrograph showing tumor cells arranged in papillary to glandular pattern. Individual tumor cells have high nuclear to cytoplasmic ratio - Endometrial Carcinoma .H\&E, 40X (Inset - 400X). 


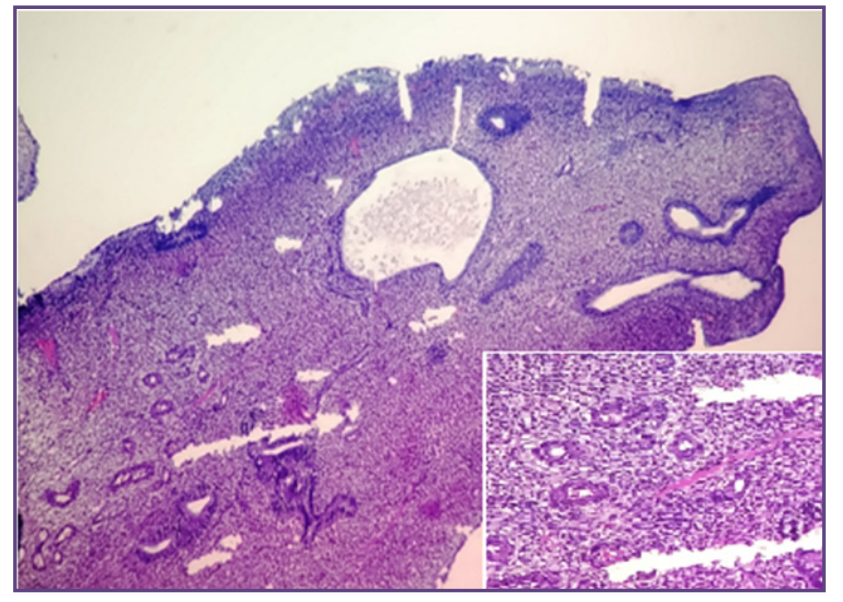

Fig. 5: Photomicrograph showing polypoidal tissue lined by epithelium in three dimensions. Stroma contains thick-walled blood vessels and few cystically dilated glands - Endometrial Polyp .H\&E, 40X (Inset - 400X).

\section{Discussion:}

In our study, AUB predominantly was seen in perimenopausal age group accounting for $48 \%$, which is comparable with study by Muzaffar et al ${ }^{[6]}$, comprising of $48.1 \%$ of AUB in perimenopausal women, Juhi Sharma et al ${ }^{[7]}$ showed similar results with majority $70.25 \%$ of cases in perimenopausal age group and Aseel Ghazi Rifat ${ }^{[8]}$ also showed $48.5 \%$ of patients in perimenopausal age group Increase in incidence of AUB in perimenopausal age group of 41-50 years may be due to the fact that these patients are in their climacteric period. As women approach menopause, cycles shorten, and often become intermittently anovulatory due to a decline in the number of ovarian follicles and their increased resistance to gonadotrophic stimulation which further causes decline in estradiol level, that cannot keep the normal endometrium growing ${ }^{[9,10]}$. Histopathological evaluation revealed Secretory endometrium in $28.39 \%$ and Proliferative endometrium in $19.75 \%$ of cases in our study, Vaidya et al reported $22.58 \%$ cases of Secretory endometrium and $18.36 \%$ cases of Proliferative endometrium in their study. Mohd Sajjad et al ${ }^{[11]}$ observed Secretory endometrium in $31.7 \%$ and Proliferative in $27.6 \%$ of cases which is almost similar to our study Bandita das et al ${ }^{[12]}$ reported $28.7 \%$ of cases of secretory endometrium in their study which is similar our study.

The main clinical complaint among our patients was menorrhagia seen in $49.38 \%$, followed by postmenopausal bleeding in $27.16 \%$ and polymenorrhagia in $9.8 \%$, which is similar to the study done by Harshitha $\mathrm{G}$ et al ${ }^{[13]}$ which showed Menorrhagia in $50 \%$ of cases and Postmenopausal bleeding in $28.3 \%$ of cases. Sajitha K et al and Juhi Sharma et al ${ }^{[14,15]}$ also noticed menorrhagia as a commonest

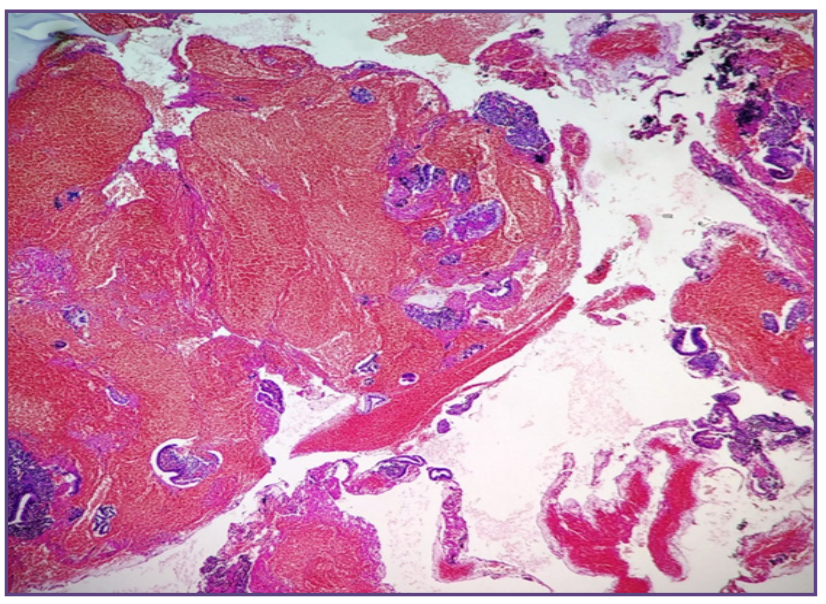

Fig. 6: Photomicrograph showing occasional endometrial glands in extensive areas of haemorrhage - Unassessable Sample. H\&E, 40X.

bleeding pattern in their study which was $47 \%$ and $57.44 \%$ respectively.

Identification of endometrial hyperplasia is important because they are thought to be the precursors of endometrial carcinoma. The overall risk of progression of hyperplasia to carcinoma is $5-10 \%$. Although this is variable according to the type of hyperplasia. From the beginning of the last century, many authors have studied the relation between endometrial hyperplasia and carcinoma and they showed a wide variation in percentage of progression of endometrial hyperplasia to carcinoma according to the type of hyperplasia ${ }^{[16,17]}$.

In our study under Organic causes AUB, the commonest histopathological finding in this category was endometrial hyperplasia which was found in $10.4 \%$ cases, out of which simple hyperplasia without atypia was seen in 12 cases, simple hyperplasia with atypia in 2 cases, Complex hyperplasia without atypia in 2 cases and complex hyperplasia with atypia in one case. Which was followed by disordered proliferative endometrium in $9.26 \%$ and endometrial polyp in $7.41 \%$ as a other pathological findings. Similar study done by Sajatha J et al showed $10.9 \%$ cases of endometrial hyperplasia, out of which simple hyperplasia without atypia were seen in 19 cases, complex hyperplasia without atypia in 4 cases and complex hyperplasia with atypia in 1 case each. Bhoomika D ${ }^{[16]}$ observed 25.3\% cases of hyperplasias in her study. ${ }^{[4]}$ Our study findings were almost similar to the study done by Vaidya et al with regards to histomorphological distribution of cases.

An age specific comparative analysis of the clinical presentation revealed that menorrhagia was the commonest complaint in $41-50$ years accounting for $60 \%$ of cases and in 
$33 \%$ of patteints $<40$ years age, which is similar to the study done by Aseel Ghazi Rifat ${ }^{[17]}$ which revealed that menorrhagia was the commonest complaint in $41-50$ years $(47.3 \%)$ and in $<40$ years age group (40.7\%). Among the other clinical presentation, the metrorrhagia was second most common complaint in $<40$-year age group whilst polymenorrhagia was the second common presentation in perimenopausal age group. The histological pattern of endometrium in patients with abnormal uterine bleeding according to their age groups, shows highest number of secretory endometrium $(51.16 \%)$ in the age group of $<40$ years followed by the 40 50 -year age group (24.36\%), which is similar to the study done by Rehan khan ${ }^{[18]}$. His study revealed largest number of secretory endometrium $(16.98 \%)$ in the age group of $<40$ years and $(12.19 \%)$ in the age group of $40-50$ years.

\section{Conclusion}

Evaluation of Endometrial samples is important in all patients with Abnormal Uterine Bleeding (AUB) to find out the Organic Pathology. Histopathological typing of endometrium is crucial for appropriate therapy. Its interpretation is quite challenging and also may show considerable interobserver variability. In AUB, the endometrial samples should be taken during the bleeding episode itself. Dilatation and curettage is a simple, cost effective, safe and reliable investigation and gives us a direct access to the target organ.

The PALM-COEIN (Polyp; Adenomyosis; Leiomyoma; Malignancy and Hyperplasia; Coagulopathy; Ovulatory dysfunction; Endometrial; Iatrogenic and Not yet classified) classification system for AUB has been approved as a FIGO classification system. This classification system has been developed with the aim that it could be used by Clinicians, Investigators, and Patients to facilitate communication, clinical care, and for Research purpose. In present study, we have tried to categorize the endometrial samples into unassessable and inadequate by using Mc Cluggage criteria.

\section{Reference:}

1. Gupta R, Porwal V, Porwal SK, Swarnkar M et al. A Retrospective Histopathological Study of 100 cases of Endometrial Curetting in Perimenopausal Women with Abnormal Uterine Bleeding. Journal of Pharm Biomedical Science 2015;05(09):757-759.

2. Sarwar A, Haque A. Types and frequencies of pathologies in endometrial curettings of abnormal uterine bleeding. International Journal of Pathology 2005;3(2): 65-70.
3. Das B, Das A. Histophological Patterns of Endometrial Biopsy in Abnormal Uterine Bleeding. Indian Journal of Applied Research. 2016; 6(6): 2249-2555.

4. Dadhania B, Dhruva G, Agravat G, Agravat A et al. Histopathological Study Of Endometrium In Dysfunctional Uterine Bleeding. Int J Res Med. 2013; 2(1);20-24.

5. Khadim M T, Zehra T, Ashraf H M. Morohological study of pipelle biopsy specimens in cases of abnormal uterine bleeding. Journal Pak Med Assoc( JPMA) 2015 Jul;65(7):705-9.

6. Sharma J, Bhargava R, Bharath V, Sharma T et al . A study of spectrum of morphological changes in endometrium in abnormal uterine bleeding. Journal of advance researches in Biological Sciences .2013; 5(4): 370-5.

7. Rosai J. Female reproductive system - Uterus - corpus. In: Rosai and Ackerman's Surgical Pathology. 10th ed. vol 2.Edinburg: Mosby; 2011: 1480-1635.

8. Sajitha K, Shetty K P, Shetty J, Kishan Prasad HL et al. Study of histopathological patterns of endometrium in abnormal uterine bleeding. Chrismed Journal of Health and Research.2014; 1( 2).

9. Berek J S et al. Editors. Novak's Textbook of Gynaecology. 15th edition. Lippencott Williams \& Wilkins. 2007.

10. Herschorn S. Female Pelvic Floor Anatomy : The Pelvic Floor, Supporting Structures, and Pelvic Organs. PMC National Library of Medicine. 2004; 6(5): S2-S10.

11. Ghani N A, Abdulrazak A A, Abdullah E M. Abnormal uterine bleeding :A histopathological study. World research journal of clinical pathology.2012;1(1):6-8.

12. Coward A,Well D. Textbook of Clinical Embryology. Cambridge University press.2013;5(4):370-75.

13. Oehler M K, Rees M C. Menorrhagia an update. Acta Obstet Gynecol Scand 2003;82:405-22

14. 14. Longacre T A, Atkins K A, Kanpson R L, Hendrickson M R .The Uterine Corpus .In: Mills S E, Cartec D, Greenson J K, Ureuter V S, Stoler M H . 5th edition. Philadelphia : Lippincott William and Wilkins ;2010:2184-2277.

15. Dijkhuizen F P, Mol B W, Brolmann H A, Heintz A P. The accuracy of endometrial sampling in the diagnosis of patients with endometrial carcinoma and hyperplasia. 2000;89(8) :1765-72.

16. Takreem A, Danish N, Razaq S. Incidence of endometrial hyperplasia in 100 cases presenting with polymenorrhagia/ menorrhagia in perimenopausal women. J Ayub Med Coll Abbottabad 2009;21(2):60-3.

17. Buckley $\mathrm{CH}$, Fox H. Biopsy Pathology of the endometrium. 2nd edition. Hoddor Arnold. 2002 March 29.

18. Padubidri VG, Daffary SN. Shaw's textbook of Gynaecology. 16th edition. Elsevier. 2014.

*Corresponding author:

Dr. Nisha J Marla, W/O Dr Jayashankar Marla, Suraj, 3-5-514/2, Kadri kambala road, Kadri mundana, Mangalore - 575004, Karnataka

Phone: +919481148975

Email: nishajmarla@gmail.com

Date of Revision : $: 24 / 12 / 2020$

Date of Acceptance : 26/12/2020

Financial or other Competing Interests: None.

Date of Publication : 30/01/2021 